\title{
Current status and sustainability issues of marine resources and biodiversity in Sudanese national red
}

\section{sea water}

\begin{abstract}
The Sudanese Red Sea is famous for its attractive and mostly pristine habitats, particularly its coral reefs. Three distinct depth zones are recognized: shallow reefstudded shelves less than $50 \mathrm{~m}$ deep, deep shelves 500 to $1,000 \mathrm{~m}$ deep, and a central trench more than $1,000 \mathrm{~m}$ deep, reaching a maximum of 3,000 meter off the city of Port Sudan. The current total annual fin fish production in Sudan is estimated to be 8000 tons from marine water (the Red sea). These marine resources divided into artisanal fishery (about 3000 tones), trawling (about 2000 tones), per sine fishery (about 2300 tones), shrimp from trawling (about 60 tones), shrimp from aquaculture (about 6 tones), trochaus (about 724 tones), mother of pearl shell (about 12 tones) and sea cucumber (about 60 tones). The Sudanese marine and coastal environment is in relatively good condition overall, with isolated badly degraded areas. The region, however, is subject to a mounting list of environmental impacts linked to urban and industrial development, and to overgrazing. Coastal habitat destruction by development; oil industry spill risks; passing ship pollution; pollution from land-based sources; risk of importing invasive species in ballast water; fisheries management; mangrove cutting and overgrazing; and marine protected areas and tourism.
\end{abstract}

Volume 7 Issue 2 - 2018

\author{
Mubarak Eisa AT,' Abdalla Nassir EA, ${ }^{2}$ \\ Abdelgadir $\mathrm{MM}^{3}$ \\ 'Department of Fisheries Science, University of Bahri, \\ Khartoum, Sudan \\ ${ }^{2}$ Fisheries research centre, Sudan \\ ${ }^{3}$ Department of fisheries, Al neelain University, Sudan
}

Correspondence: Mubarak Eisa AT, Department of Fisheries Science, college of natural resources \& environmental studies, University of Bahri, Khartoum, Sudan,

Email mubaraktbn@gmail.com

Received: February 24, 2018| Published: April 19, 2018

Keywords: marine resources, red sea, sustainability, conservation

\section{Introduction}

Three distinct depth zones are recognized: shallow reef-studded shelves less than $50 \mathrm{~m}$ deep, deep shelves 500 to $1,000 \mathrm{~m}$ deep, and a central trench more than $1,000 \mathrm{~m}$ deep, reaching a maximum of 3,000 m off the city of Port Sudan. ${ }^{1}$ The only assessment on marine stock was reported by Chakraborty ${ }^{2}$ to be 35 thousands tones. The current total annual fin fish production in Sudan is estimated to be 8000 tons from marine water (the Red sea). These marine resources divided into artisanal fishery (about 3000 tones), trawling (about 2000 tones), per sine fishery (about 2300 tones), shrimp from trawling (about 60 tones), shrimp from culture (about 6 tones), trochaus (about 724 tones), mother of pearl shell (about 12 tones) and sea cucumber (about 60 tones). However, the exact quantitative values of each marine livestock are absent.

The marine fisheries of the Sudanese territorial waters in the Red Sea are the best preserved ecosystems in the country. To date, these precious assets have been largely protected by the lack of development, but the economic and shipping boom focused on Port Sudan and the oil export facilities is rapidly changing the environmental situation for the worse. There are five marine resources need to be focused on, these are corals reefs, marine invertebrates, marine fine fish, sea weeds and mangroves. Better knowledge on the distribution and density of fish is lacking and required. ${ }^{1}$

\section{Marine biodiversity}

\section{Coral reefs}

There are three types of coral reefs found in the Red Sea water within Sudanese boarders, namely, fringing reefs, (lie 1-3 km offshore); patch reefs, (lie up to $15 \mathrm{~km}$ offshore), separated from the fringing reef by deep and wide channels; and pillar reefs or atolls, (20 $\mathrm{km}$ or more Offshore), such as the Sanganeb atoll. An extensive cover of algae over some fringing reefs, however, the majority of coral reefs are considered to be in moderate to good health. ${ }^{3}$

\section{Mangroves}

Mangroves which are form nesting and breeding grounds fish and other marine invertebrates, such as shrimps, provide forage, trapping of sediments, consolidation of the shoreline habitats, nesting and roosting sites for several avian fauna, enriching the marine food web in the surrounding oligotrophic water, coastal protection from erosion and wood products. The indigenous species of mangroves in Sudanese Red Sea shores are Rhizophora mucronata, Avicennia marina and Bruguiera gymnorrhiza. ${ }^{4}$ Extensive stands were originally found in areas where the seasonal streams (khors) reach the coast, along coastline, as these produce the brackish and sediment-rich conditions necessary for mangroves to thrive.

\section{Sea grass beds}

Sea grass beds are found in shallow coastal waters, around mangroves and between the low tide line and fringing reefs. They are highly productive habitats that provide grazing for dugong, and support fish and trochus shellfish.

\section{Marine invertebrates}

Marine invertebrates are an important source of secondary and / or seasonal income for the coastal communities of the area. The most important of them are sea cucumbers (also termed beche-demer, particularly in their processed state); the gastropods Trochus and Strombus and, to a much lesser extent Lambis, Murex and Tridacna. A fishery for wild Pinctada (Pinctada margaritifera) is also reported to still exist, although this appears to presently be at a very low level of intensity. These invertebrate fisheries are largely seasonal, 
taking place mostly over the summer months, and are entirely or almost entirely cash fisheries for export from the area. Buyers for the products of these fisheries are either from Port Sudan or from outside Sudan altogether, and almost all of the products, with the possible exception of meat from some of the gastropods, are exported from Sudan. The sea cucumber fishery in particular is carried out by nonlocal fishers for a non-local company, and little or no benefit from this fishery accrues to the people of the Park. ${ }^{5}$

\section{Threats facing marine resources}

The expected risk facing marine resources and biodiversity will come from petrol terminal, which now oil spill from tanker destroyed and polluting the rearing fish. Most severe threats to reefs come from maritime shipping and dredging. ${ }^{6}$ The tourism sector contributes to damage of reefs by anchor and flipper damage. ${ }^{7}$ The percentage of hard live coral at Abu Hashish Jetty ranged from $23.5 \%$ at $10 \mathrm{~m}$ depth and $50 \%$ at $5 \mathrm{~m}$, while dead coral (DC) ranged from $2.5 \%$ at 10 $\mathrm{m}$ depth and $0 \%$ at $5 \mathrm{~m}$ depth. At Bashaer Oil Exporting Port HC covered $37.5 \%$ while DC covered $21.25 \%$ of the 12 substrate. At Arous, dead corals covered $51.25 \%$ of the substrate and no bleaching was observed below $4 \mathrm{~m}$. Bleached corals were observed at the top of the fringing reef at $2 \mathrm{~m}$. Overall bleached corals were estimated to cover $14 \%$ of the substrate. ${ }^{7}$

Mangroves along the Sudanese Red Sea coast are under constant anthropogenic pressure. ${ }^{8}$ The grazing of animals (camels), blocking of fresh water come from khors to shoreline and build of tourist villages have destructive impact of mangroves. Mangroves in the Region are on government-owned land, under the jurisdiction of various authorities. ${ }^{9-13}$ Overfishing and action of trawling is causing loud debates, among scientists and policy makers at all levels, on its negative effects on whole mine ecosystem starting from coral reefs up marine invertebrates. ${ }^{5}$

Many of the threats facing marine ecosystems which have been identified in the Sudanese coastal waters are related to a lack of planning and management of development in the coastal zone, limited use of environmental assessment procedures in making investment decisions, and the in adequate enforcement of existing laws.

\section{Marine biodiversity conservation}

The coastal and marine ecosystem has been used by the inhabitants of the region in a sustainable manner for thousands of years. ${ }^{14}$ Fishing activities in the Red sea are carried out by the artisanal sector using traditional gear, craft, and fishing techniques and are confined to the near shore area, targeting finfish, shrimp, mollusks and sea cucumbers. There are three main Marine protected areas (MPAs) in the Red Sea State (Sanganeb MPA, Dungonab Bay and Muakwwar Island MPAs). ${ }^{15}$

In 2005, two protocols were signed by Sudan, namely, 'The Protocol Concerning the Conservation of Biological Diversity and the Establishment of Protected Areas' and the 'Protocol Concerning the Protection of the Marine Environment from Land-Based Activities in the Red Sea and Gulf of Aden'. Both Protocols are additions to the 'Regional Convention for the Conservation of the Red Sea and Gulf of Aden Environment' ${ }^{16}$ Survey design guidelines for marine protected areas (MPAs) have been prepared by PERSGA and ecological and socio-economic surveys have been completed at Mukawwar Island and Dungonab Bay MPA. Site-specific master plans, with management guidelines, have been written for Dungonab Bay and Mukawwar Island MPAs with the involvement and participation of local stakeholders. ${ }^{17}$

\section{Conclusion}

The capacities of HCENR, as the focal point for marine biodiversity need to be strengthened to fulfill its mandate in accordance with the Environment Conservation Act 2001. Serious efforts and large resources are needed to upgrade the conservation status of the protected areas in Southern Sudan. Research and data collection regarding taxonomy and conservation need to be the current issue of department concern in Sudanese universities fisheries research centre.

National Action Plans for corals, turtles, seabirds, mangroves (that build on the Regional Action Plans) need to be developed as a priority and provided with sufficient funding support to allow them to be implanted. Need to reduce camel grazing in mangroves and the felling and cutting of mangrove trees. Efforts to manage camel grazing and wood collecting require alternative sources of food, fuel and construction materials to be provided.

There is a need to develop community education programs that highlight the impacts of coastal communities on reef ecology, including degradation, anchor damage, littering, waste disposal and souvenir collection. These could be integrated with programs of community-based monitoring that involve recreational scuba divers or fishers.

Several plans and studies have been done in the Sudanese Red Sea coast to promote fishing activities and fisheries sectors, some of these done by government institutes, international organization and some by individual researchers. ${ }^{18-20}$ The European Commission (2009), supported fisheries sectors around the Sudanese Red Sea Coast by technical assistance in establishing fishery forum to manage the marine resources.

\section{Acknowledgements}

None.

\section{Conflicts of interests}

Author declares that there is no conflict of interest.

\section{References}

1. Mishrigi YS, Ali MS, Abdalla AA. Identification study for Sudan Red Sea fisheries. Ministry of Economic Planning and Investment project. Report. 1993.

2. Chakraborty D. Marine fisheries statistics in Sudan-an expanded plan of development. FAO. Rome. 1983. 39 p.

3. Elawad AN. Some biological aspects of fish by-catch from Sudanese Red Sea Shrimp Trawling. MSc, University of Khartoum, Department of Zoology, Khartoum. 2002. 133 p.

4. PERSGA/GEF. Status of mangroves in the Red Sea and Gulf of Aden. PERSGA Technical Series No. 11. PERSGA, Saudi Arabia. 2004.

5. Tesfamichael D, Ekawad AN. Reconstructing Red Sea fisheries of Sudan: foreign aid and fisheries. In: Tesfamichael D, Pauly D, editors. Catch reconstruction for the Red Sea large marine ecosysytem by countries (1950-2010). Fisheries Centre Research Reports. Fisheries Centre, University of British Columbia. 2012. p. 51-70. 
6. Branford JR. Penaeid shrimps in the Tokar Delta Region of the Red Sea in "proceedings of symposium on the coastal and marine environment of the Red Sea, Gulf of Aden and tropical western Indian Ocean. University of Khartoum, Sudan. 1980.

7. Nicolas P, Abdullah A. Regional Status of Coral reefs in the Red SEA and the gulf of Aden-Middle East. 2001. p. 1-35.

8. Sabeel RA, Vanreusel A. Potential impact of mangrove clearance on biomass and biomass size spectra of nematode along the Sudanese Red Sea coast, Marine Environ Res. 2015;103:46-55.

9. Mohamed BF. Ecological observations on the mangroves of the Red Sea shores of the Sudan. Hydrobiologia. 1984. 10(1):109-111.

10. Mandura AS. Amangrove stand under sewage pollution stress. Mangroves and Salt Marshes. 1997. 1(4):255-262.

11. Mandura AS, Khafaji AK. 1993. Human impact on mangrove of KhorFarasan Island, Southern Red Sea Coast of Saudi Arabia. In: Leith H, Al Masoom H, editors. Towards the rational use of high salinity tolerant plants. Dordrecht, Kluwer Academi Publishers; 1:353-261.

12. Khalil ASM. Status of Mangroves in the Republic of Sudan (Draft Report) PERSGA, Saudi Arabia. 2003
13. Wilkei ML. Mangrove Conservation and Management in the Sudan. FAO Report. Ministry of Environment and Tourism, Khartoum \& FAO, Rome. 1995

14. Vine P. Pearls in Arabian Waters. Immel, London. 1986.

15. UNIDO. Surveys of Renewable Marine Resource: Independent Final Evaluation in the Red Sea State. Republic of the Sudan. Austria. 2014.

16. Jeddah Convention. The Regional Convention for the Conservation of the Red Sea and the Gulf of Aden Environment. Jeddah 21583, Kingdom of Saudi Arabia. 1982.

17. HCENR. Sudan's Fourth National Report to the Convention on Biological Diversity. The higher council for Environment and Natural Resources. Ministry of Environment and Physical Development. 2009.

18. Elawad AN. Sudan National Report to the Scientific Committee of the Indian Ocean Tuna Commission. National Reports to the IOTC Scientific Committee in 2013.

19. Erik O. First survey of renewable marine resources in the Red Sea State, Republic of Sudan. 2012. 1-30.

20. Moshira H, Mohammed MAK, Abdulmohsin AA. Status of the coral reefes of the world. 2002. 